\title{
THE MICROBIOME AND EPIGENOME PROFILE IN PEDIATRIC TYPE 1 DIABETES IN QATAR
}

\section{Rama Bakhash, Farzana Sulaiman}

Supervised by: Dr. Mashael Al-Shafai, Dr. Annalisa Terranegra

${ }^{1}$ Biomedical Science Department, College of Health Sciences, Qatar University, Doha, Qatar

2Sidra medicine, Doha, Qatar

\section{ABSTRACT}

This study focused on Qatar's pediatric population that has witnessed a steep increase in the incidence of the disease. In order to understand this, we analyzed the blood and stool samples of a pilot group of 21 T1D subjects (age 6-12 yrs. old) for the microbiome composition, Short Chain Fatty Acid (SCFA) levels and methylation profiles using 16s rDNA sequencing, gas Chromatography and Infinium methylation assay respectively.

\section{INTRODUCTION}

T1D is characterized by immune destruction of pancratic $\beta$-cells directed by autoantibodies against islet cells autoantigens. The genetic factors are the key factors in the development of the etiology and pathogenicity of the disease. Other factors are contributing strongly for the onset of the disease including complex interactions among genes, immune response, environmental factors, gut microbiota and diet.

\section{RESULTS}

T1D patients have higher fraction of Bacteroidetes followed by Firmicutes. In the uncontrolled (>7.5\% HbA1C) T1D patients there is an abundance of Prevotella 9 strain in genus level (figure 1), SCFA analysis indicated a dramatic decrease in ethanoic, propionic and butanoic acids (figure 2) and considerable fluctuation in DNA methylation levels (figure 3).

\section{IMAGES}
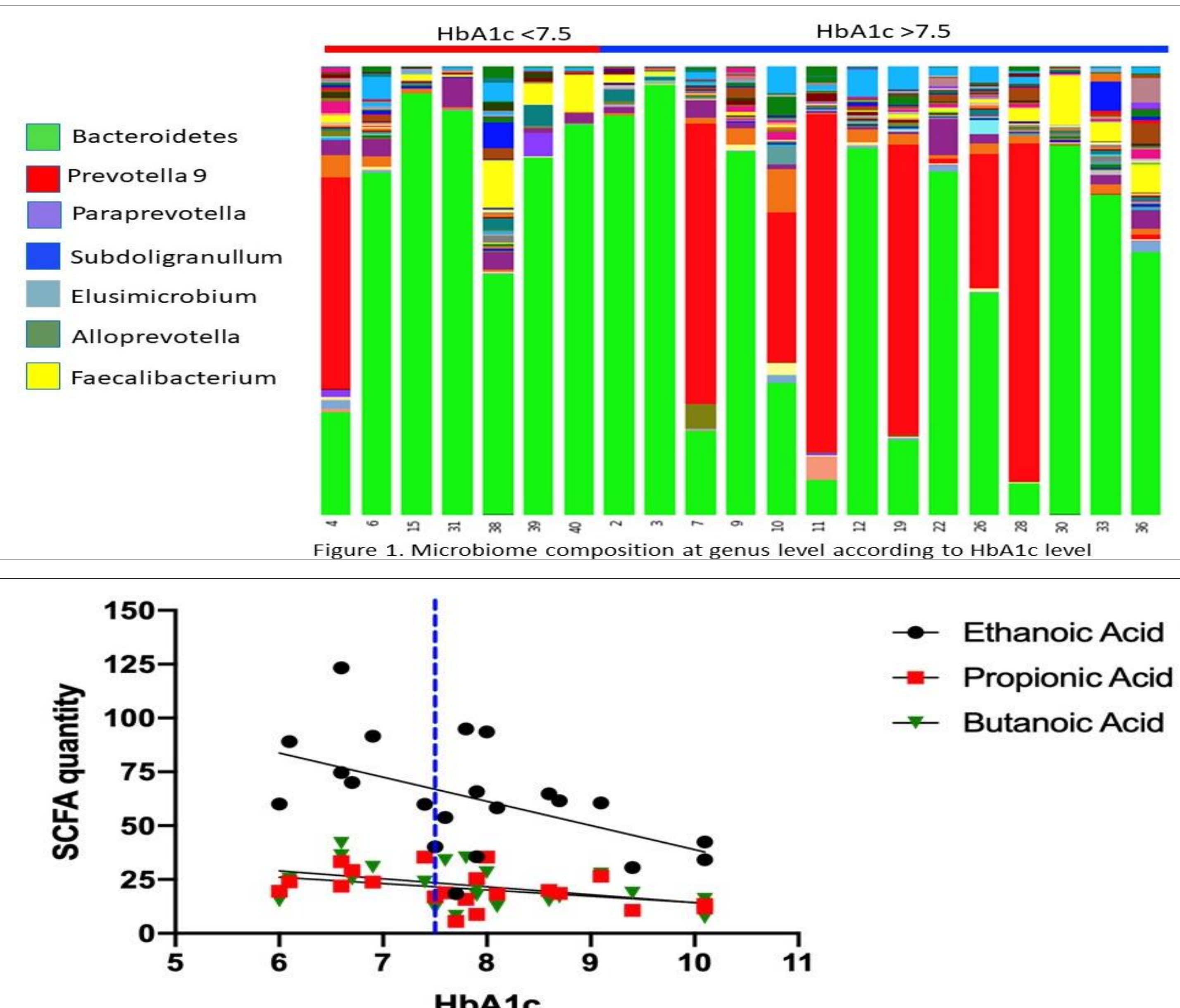

- Ethanoic Acid - Propionic Acid - Butanoic Acid Figure 2. Trend of three short chain fatty acids with the increase of HbA1c levels.

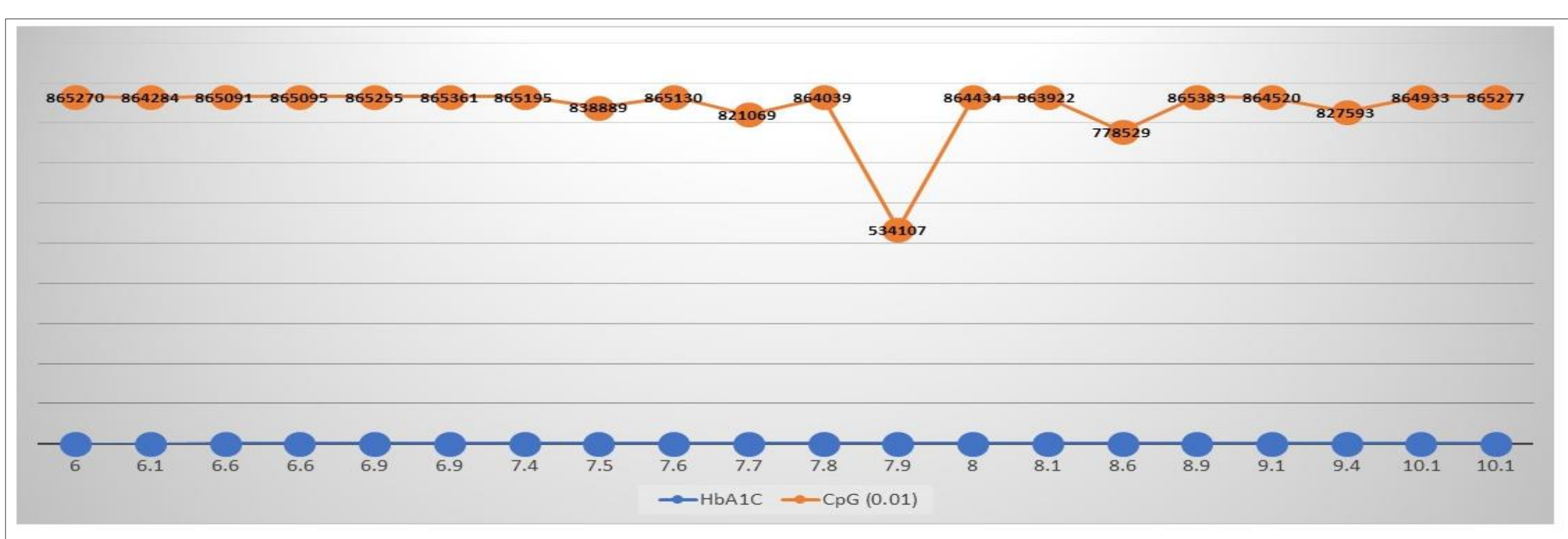
40. 38 15. 36. 30. 33. 12. 28. Figure 3. DNA methylation profiling according to HbA1c levels.

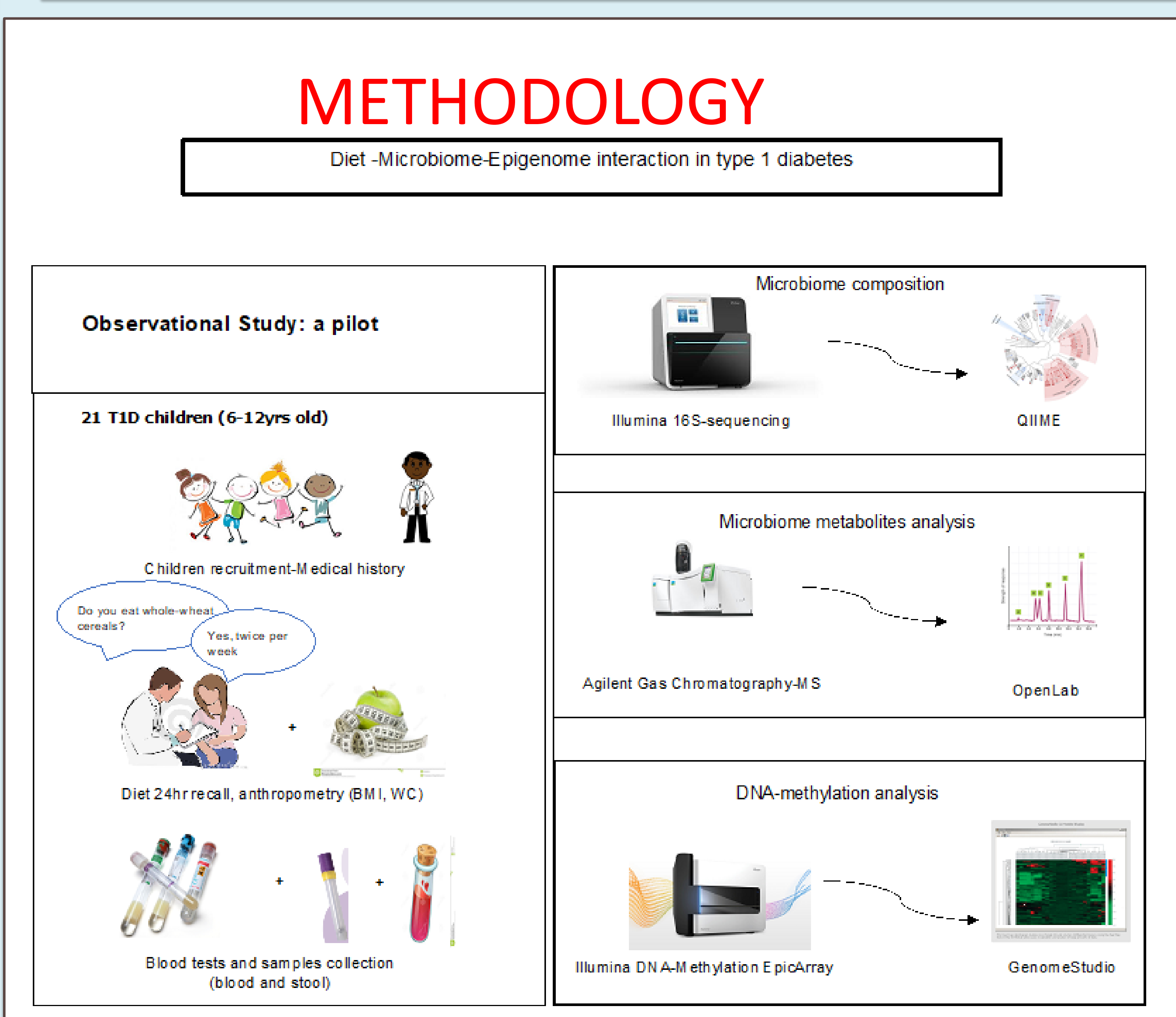

\section{CONCLUSION}

We can hypothesize that changes in gut microbiota, through its metabolites like SCFA, can modulate epigenetic patterns with an impact on $T 1 D$ reducing the effect of the treatment. We will continue the DNA methylation data analysis to identify the locus and genes the impact on the gene expression and use the result as a clinical biomarker for T1D.

\section{REFERENCES}

1- Agilent-Technologies. OpenLAB Software Suite. Retrieved from http://www.agilent.com/enus/products/softwareinformatics/openlab-softwaresuite

2- Alkanani, A. K., Hara, N., Gottlieb, P. A., Ir, D., Robertson, C. E., Wagner, B. D., . . Zipris, D. (2015). Alterations in Intestinal Microbiota Correlate With Susceptibility to Type 1 Diabetes. Diabetes, 64(10), 3510-3520. doi:10.2337/db14-1847

\section{ACKNOWLEGEMENTS}

Alhamdulillah, completing this project would have been almost impossible without the blessings of Allah in all aspects. The support we received from Dr. Mashael Alshafi and Dr. Annalisa Terranegra. Finally, the special thanks for the major support system we had from our parents and families. 